Open Access

\title{
Impacts of corn price and imported beef price on domestic beef price in South Korea
}

\author{
GwanSeon Kim and Tyler Mark ${ }^{*}$ (D)
}

\author{
* Correspondence: \\ tyler.mark@uky.edu \\ Department of Agricultural \\ Economics, University of Kentucky, \\ Lexington, KY, USA
}

\begin{abstract}
South Korea is one of the largest beef importing countries in the world. Australia, USA, and New Zealand provide the majority of beef they import. The objective of this study is to evaluate the price relationship of Korean cattle and corn, prices of the imported beef and corn, and prices of Korean cattle and imported beef. We examine threshold points using threshold vector autoregressive (TVAR) model by assuming the presence of nonlinearity. We find that there are two thresholds in Australian beef price with first difference data. This study finds that the current Korean beef price is positively affected by increasing in the previous month of Australian beef price in first and second regimes. Changing in previous corn price has no significant impact on current Korean cattle price in the second regime. In the third regime, we find that current Korean cattle price is positively affected by previous corn price whereas no impact from previous Australian beef price. In this study, we could not use data for the USA due to the periods of bovine spongiform encephalopathy (BSE). However, we expect that current Korean beef price is significantly affected by changing in the previous month of US beef price using data after the periods of BSE.
\end{abstract}

Keywords: Korean beef prices, Structural change, Threshold, BSE

\section{Background}

South Korea is the fifth largest beef import country out of 58 countries, which is equivalent to $7 \%$ of the world, followed by USA, Russia, Japan, and Hong Kong (Cook 2016). In 1976, Korea started to import beef, and the domestic market was fully opened due to the tariff and import quotas by Uruguay Round of Multinational Trade Negotiation (UR) in 2001. According to the Korea Institute for Animal Products Quality Evaluation (KAPE), imported beef quantities in 2013 were 56\% from Australia, 35\% from USA, 9\% from New Zealand, and 1\% from Canada, respectively (KAPE 2013). However, the USA was the largest exporter of beef to South Korea before 2003. In 2003, a dairy cow in Washington State was discovered to have bovine spongiform encephalopathy (BSE), and Korea banned beef imports from the USA on December 2003 (Giamalva 2013, Park et al. 2008). Based on US Department of Agriculture, Economic Research Service (USDA ERS 2012), beef imports from Australia and New Zealand have increased since December 2003 due to the BSE outbreak in the USA. This ban lasted until July 2008 when the ban was lifted and the USA resumed exporting beef to South Korea.

(c) The Author(s). 2017 Open Access This article is distributed under the terms of the Creative Commons Attribution 4.0 International License (http://creativecommons.org/licenses/by/4.0/), which permits unrestricted use, distribution, and reproduction in any medium provided you give appropriate credit to the original author(s) and the source, provide a link to the Creative Commons license, and indicate if changes were made. 
According to the Ministry of Agriculture, Food, and Rural Affairs in South Korea, the proportion of imported formula feed is 53\% in total feed; in addition, a proportion of imported corn is 79\% of total feed grains (MAFRA 2015). Corn is one of the most important feed grains used in beef production. Hebert and Anderson (2011) mention the exogenous effect arising as a consequence of a negative relationship between corn and beef prices. In this study, we hypothesize that change in corn prices will significantly and directly affect both imported beef prices from Australia and prices of Korean native cattle. Given that Korea has to import a large percentage of their feed used in Korean native cattle, small changes in the world corn prices could have significant impacts on the cost of production both within and outside of Korea. In addition, Korean beef prices are also affected by changes in imported beef prices. Figure 1 shows how corn, wheat, and soybean prices are changed over time from 1960 to 2015. Based on Fig. 1, prices of corn, soybean, and wheat move together, so focusing on changes in corn prices will provide information on how prices of beef will be affected if there is a shock in corn price. Table 1 shows the results from the correlation test between the commodities, and the results show that there is a strong and positive correlation among the commodities.

In this study, we focus on imported beef prices from the Australia because the imported beef quantities from Australia are relatively higher than other countries: 20.91\% higher than USA, $47.12 \%$ higher than New Zealand, and $55.22 \%$ higher than Canada. In addition, data for the imported beef prices and quantities from USA are not available from 2003 to 2008, due to the ban on US beef (Marsh et al. 2008). By 2013, Korea had increased imports to $35 \%$ from the USA, making it the second largest exporter of beef to Korea.

The primary objective of this study is to evaluate the relationship between Korean native cattle prices and imported corn and beef prices. Specifically, we evaluate the presence of structural break points by assuming that there are structural changes due to the BSE outbreak. The outbreak of BSE created a fundamental change in the Korean beef market in 2003. With the announcement of the BSE outbreak, the beef imports from Australia began to increase, changing the relationship between Korean native

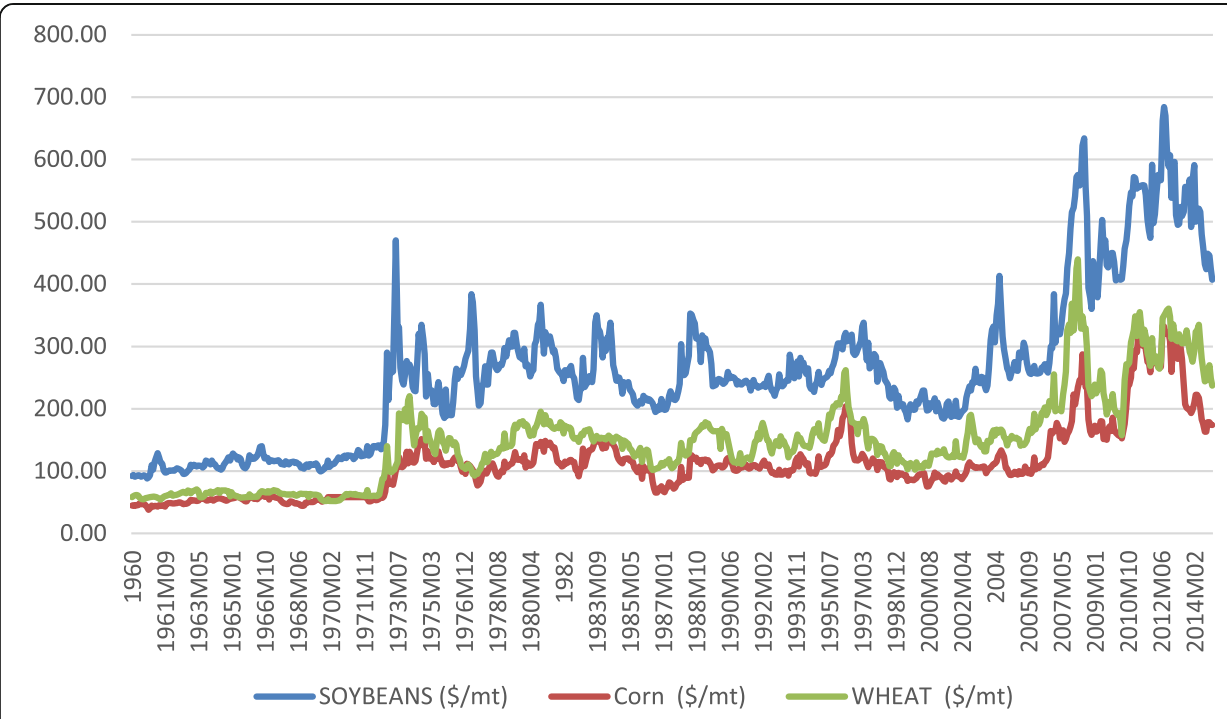

Fig. 1 Prices movement between soybean, corn, and wheat (in nominal \$) 1960-2015 
Table 1 Correlation test between commodities

\begin{tabular}{llll}
\hline & Soybeans $(\$ / \mathrm{mt})$ & Corn $(\$ / \mathrm{mt})$ & Wheat $(\$ / \mathrm{mt})$ \\
\hline Soybeans $(\$ / \mathrm{mt})$ & 1 & & \\
Corn $(\$ / \mathrm{mt})$ & 0.939 & 1 & 1 \\
Wheat $(\$ / \mathrm{mt})$ & 0.937 & 0.935 & 1 \\
\hline
\end{tabular}

cattle prices and corn and beef import prices. Therefore, we hypothesize the relationship before and after certain structural breakpoints are statistically different.

Studies that examine BSE impact utilizing structural breaks are limited. Sanjuan and Dawson (2003) investigated producer-retail price transmission for beef, lamb, and pork by considering the BSE crisis in the UK. Jin et al. (2008) examine the impact of North American BSE cases on daily live cattle future prices. However, the literature on overall BSE impact is more developed. Lloyd et al. (2006), Saghaian (2007), and Hassouneh et al. (2010) investigate the impact of BSE on price transmissions in the beef market. Both Lloyd et al. (2006) and Hassouneh et al. (2010) address issues of human health and food scares within the UK and Spain by examining the impact of BSE on the retail and producer levels. They find different impacts between beef producers and retailers. However, the main difference between studies is that Lloyd et al. (2006) did not consider any threshold component. Saghaian (2007) evaluated the implications of the 2003 BSE outbreak on a feedlot, wholesale, and retail beef prices. They find that beef prices overall were negatively affected by the BSE discovery even though the magnitude of price effects are different for each price series. Park et al. (2008) investigate impacts of animal disease outbreaks on Korean meat market. They employ a vector error correction (VEC) model by applying known structural break points where the animal diseases are actually discovered and then conduct out-of-sample forecasting for meat prices after the period of the event. Based on our knowledge, no study investigates how domestic beef price in South Korea is affected by imported beef price and imported corn price by considering structural change due to BSE.

Furthermore, we employ a threshold framework to examine nonlinearity between the variables by hypothesizing that price effects are statistically different at certain threshold points. We assume that the structural break is a consequence of the import ban, based on the literature and increases in Australian beef imports. Nonlinearity is considered from a theoretical standpoint, and empirical studies have also shown its existence in time series data. Goodwin and Holt (1999) and Goodwin and Harper (2000) state the potential issues of nonlinear and threshold type adjustments in error correction models have been recognized in recent time series analysis. In addition, the dynamic price responses may be caused by a nonlinear nature due to the different combinations of adjustments from alternative regimes by threshold specifications. Especially, Goodwin and Harper (2000) point out that many recent time series models examining price transmission consider asymmetric adjustments assume that the price transmission process to be fundamentally linear. Also, Zivot and Wang (2007) mention that nonlinear behavior in economic time series allows not only the presence of different regimes but also the dynamics to be different in different regimes. In addition, Luoma et al. (2004) argue that linear models in a nonlinear situation result in the estimation of incorrect inferences.

Other studies that investigate price relationship of meat utilizing a threshold model are as follows. Abdulai (2002) examines the relationship between producer and retail 
pork prices in Switzerland using threshold autoregressive (TAR) and momentumthreshold autoregressive (M-TAR) models. Based on TAR and M-TAR, the author finds evidence of asymmetric pricing behavior on the part of pork retailers. Luoma et al. (2004) investigate the asymmetric price transmission between producer and consumer in Finnish beef and pork markets by using monthly price data from January 1981 to May 2003. They employ a Bayesian multiple-regime vector error correction model. Serra et al. (2006) investigate price transmission relationship between EU pork markets using nonlinear methods from 1994 to 2004. They employed a nonparametric technique (LLR) and compared it with a parametric technique (TAR). Based on both parametric and nonparametric techniques, they find that Spain and Germany, which are two leading EU pork producers, have symmetric price adjustment whereas price transmission processes are asymmetric between Germany, Demark, and France.

This study provides the following contributions to the literature. First, it provides economic implications of the domestic price dynamics in response to the 2003 BSE outbreak. Price dynamics are explored for changes in world corn prices and their transmission into domestic Korean beef prices and imported beef prices. Secondly, this study evaluates the presence of threshold nonlinearities. Finally, based on our knowledge, no study investigates and finds the impact of imported Australian beef price and corn price on the Korean beef market with different threshold points under the assumption of the nonlinearity.

Data

Data for this study comes from multiple sources. Table 2 includes the variable descriptions and summary statistics for the key variables. The primary variables are the Korean native beef price, world corn price, and the imported Australian beef price. Data for Han-Woo prices or Korean native beef price is from the KAPE. Imported beef prices are sourced from Korea Customs Service (KCS). Corn prices are obtained from the World Bank and adjusted using the real exchange rate from the Bank of Korea (BOK). Since there is limited data availability especially for Han-Woo prices, we use monthly time series data from 2000 to 2014. An initial observation is that the price of Korean beef is almost three times higher than the price of the imported Australian beef. There are two possible reasons to explain the price difference between Korean beef and imported Australian beef. First, South Korea does not put the cattle out to pasture due to land constraints compared to cattle in Australia. Second, most feed grains used for cattle are imported. Figure 2 shows how each variable moves over time from 2000 to 2014.

\section{Methodologies and conceptual frameworks \\ Structural break with unit root test}

According to Baum (2001), results from tests of Dickey-Fuller (DF), Phillips-Person (PP), and Dickey-Fuller using a generalized least square (DF-GLS) for the unit root

Table 2 Summary statistics

\begin{tabular}{lllllll}
\hline Variable & Description $($ won $/ \mathrm{kg})$ & Obs & Mean & Std. dev. & Min & Max \\
\hline KORP & Price of Korean native cattle & 178 & $13,291.83$ & 1905.46 & 8677.00 & $18,625.00$ \\
CORNP & Imported corn price & 178 & 184.98 & 82.26 & 83.92 & 380.46 \\
AUSP & Imported Australian beef price & 178 & 4163.63 & 1147.44 & 2034.33 & 6118.35 \\
\hline
\end{tabular}




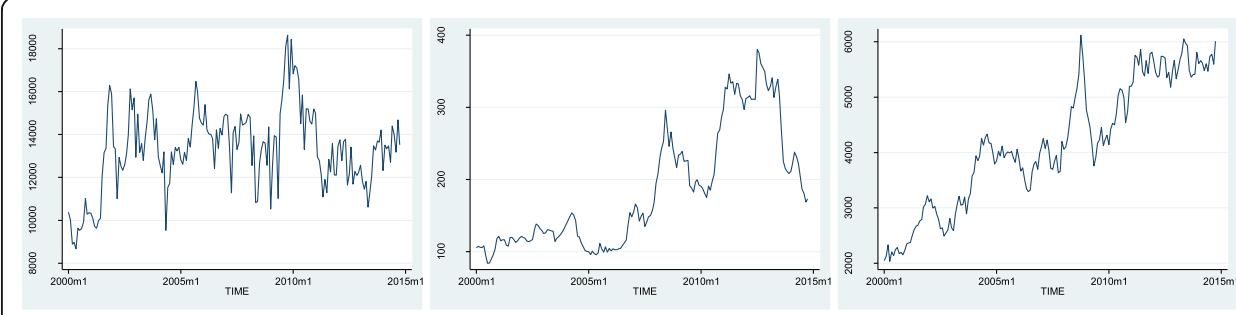

Fig. 2 Monthly data for each variable from 2000 to 2015

may cause bias in that the model excluding structural change leads to misspecification by omitting relevant independent variables. Baum (2001) suggests using a technique based on Perron and Vogelsang (1992) for the unit root test in the presence of one structural break. Perron and Vogelsang (1992) describe that the additive outlier (AO) is used when the change is assumed to affect instantaneously whereas the innovational outlier (IO) model for slowly changing. In this study, we assume the change by BSE affect instantaneously, and the Clemente-Montañés-Reyes unit root test with single mean shift (also called AO) model is used in this study.

For the conceptual framework for the AO model, we follow the original paper by Perron (1990). The null hypothesis that the series $y_{t}$, which is a realization of a time series process, is considered by the presence of a unit root, but the standard classification is generalized in order to allow a one-time change in the structure of the series at a time $T_{B}$ where $\left(1<T_{B}<T\right)$. Then, the null hypothesis can be rewritten as:

$$
y_{t}=\gamma D(T B)_{t}+y_{t-1}+w_{t}(t=1 \ldots, T)
$$

where $D(T B)_{t}=1$ if $t=T_{B}+1$ and 0 otherwise; $y_{0}=y(0)$ either a fixed constant or a random variable. In order to use a functional central limit theorem for partial sums $S_{t}$ $\sum_{j=1}^{t} w_{t}$, the conditions on the sequence of innovations $w_{t}$ are specified. With Gaussian innovation, a series $w_{t}$ is generated by any finite order ARMA $(p, q)$ process. When conditioning upon the initial observation $y_{0}$, the mean of the series $y_{t}$ is given by $y_{0}$ up to time $T_{B}$ and by $y_{0}+\gamma$ afterward under the null hypothesis. However, the series do not contain a unit root under the alternative hypothesis, and the model can be defined as follows:

$$
y_{t}=\mu+\gamma D U_{t}+e_{t}
$$

where $D U_{t}=0$ if $t \leq T_{B}$ and 1 otherwise. Here, the conditions on $e_{t}$ are general enough to permit an ARMA $(p+1, q)$ representation consistent with the process.

\section{Generalized least square Dickey-Fuller test}

The DF-GLS is used to test unit root in time series, and this test was proposed by Elliott et al. (1996) who find that test from the DF-GLS is significantly larger power than the augmented Dickey-Fuller test. Following discussion follow Stock and Watson (2012). The augmented Dickey-Fuller test includes fitting a regression of the form as follows: 


$$
\Delta y_{t}=\alpha+\beta y_{t-1}+\delta t+\gamma_{1} \Delta y_{t-1}+\cdots+\gamma_{p} \Delta y_{t-p}+\varepsilon_{t}
$$

The testing null hypothesis is $H_{0}: \beta=0$. The null hypothesis explains that $y_{t}$ is a random walk or it possibly has drift. The alternative hypothesis is that $y_{t}$ is either stationary with linear trend or nonzero mean with no trend.

\section{No cointegration vs threshold cointegration test}

We test whether there is a threshold cointegration between the variables or not. It is important to be tested in this paper because threshold vector autoregressive (TVAR) or threshold vector error correction model (TVECM) can be used based on results of the cointegration test. The TVAR is appropriate if there is no threshold cointegration whereas the TVECM is appropriate if there is threshold cointegration. The test can be done by using the Seo test, which was introduced by Seo (2006). The threshold cointegration was initially introduced by Balke and Fomby (1997). According to Seo (2006), a standard linear cointegration is explained by the threshold cointegration due to the fact that it allows adjustment to long-run equilibrium to be nonlinear or not. The conceptual framework for testing the linear no cointegration null in a TVECM follows Seo (2006). The test for the linear no cointegration null hypothesis can be defined as $H_{0}: \alpha_{1}=\alpha_{2}=0$ from the model below:

$$
\varnothing(L) \Delta x_{t}=\alpha_{1} z_{t-1}\left\{z_{t-1} \leq \gamma_{1}\right\}+\alpha_{2} z_{t-1}\left\{z_{t-1}>\gamma_{2}\right\}+\mu+\varepsilon_{t}
$$

where $t=1, \ldots . n$, and $\varnothing(L)$ is qth-order polynomial in the lag operator, so it can be written as $\varnothing(L)=\mathrm{I}-\varnothing_{1} L^{1}-\cdots-\varnothing_{q} L^{q}$. For a known cointegrating vector $\beta$, the term for the error correction is defined as $z_{t}=x_{t}^{\prime} \beta$. The threshold parameter $\gamma=\left(\gamma_{1}, \gamma_{2}\right)$ satisfying $\gamma_{1} \leq \gamma_{2}$, which takes values on a compact set $\Gamma$. The model above allows for the no-adjustment region in the middle $\left(\gamma_{1}<z_{t-1} \leq \gamma_{2}\right)$.

\section{Empirical results}

\section{Structural break unit root test}

Initially, we assume that the short-run and long-run relationships between the variables are substantially different with different structural break points due to the BSE. In addition, the different structural break points come from the nonlinearity. Table 3 shows the result from the Clemente-Montañés-Reyes unit root test with single mean shift (also called AO) model. In Table 3, du1 and rho -1 represent time structural break and unit root, respectively. The optimal structural break points for prices of Korean cattle beef, imported corn, and Australia beef are April 2001, July 2008, and August

Table 3 Results from the Clemente-Montañés-Reyes unit root test with single mean shift (AO) model

\begin{tabular}{llll}
\hline & KORP & CORNP & AUSP \\
\hline du1 & $3821.87^{* * *}$ & $133.68^{* * *}$ & $1909.20^{* * *}$ \\
& $(9.33)$ & $(17.98)$ & $(15.04)$ \\
rho -1 & -0.28 & -0.12 & -0.07 \\
& $(-3.09)$ & $(-3.05)$ & $(-2.88)$ \\
Optimal break point & 2001 April & 2008 July & 2010 August \\
\hline
\end{tabular}

***1\% significant levels Parenthesis indicates $t$ statistics 
2010, respectively. We can interpret the result of the unit root test that we cannot reject the null hypothesis of a unit root in series of three variables despite the structural break. In other words, all three variables are nonstationary even though we take into account the structural break. Figure 3 shows graphical structural break points. Based on results from Table 3, we find that we have approximately 1-year pre-structural break and 4 years of data post the structural breakpoint, which are not enough observations to compare and find the short-run and long-run relationships. Even though this study cannot further investigate short-run and long-run price relationships before and after the structural break points due to lack of observations, this finding provides and supports new consideration and evidence of nonlinearity in times series. This finding also contributes to the existing literature related to price adjustments by BSE crises and the need to use new methodologies to detect nonlinearity problems.

There are two main sources to cause nonlinearity in time series analysis. According to the Giordani et al. (2007), the presence of nonlinearity is caused by the structural change; however, Goodwin and Holt (1999) mention that the threshold effects occur when larger shocks induce a different response compared to smaller shock, and this dynamic response is due to the nonlinearity. Even though we are unable to observe short-run or long-run relationships by considering different structural changes, we do observe the threshold points by assuming the presence of nonlinearity from the fluctuation of variables as shown in Fig. 2.

\section{DF-GLS unit root test}

First, we conduct unit root test by using DF-GLS proposed by Elliott et al. (1996) who find that DF-GLS is statistically powerful than the commonly known Dickey-Fuller test. Table 4 shows the results from the DF-GLS unit root test. Based on the results, we find that there is no unit root (i.e., variables are stationary) for both constant with the trend and without trend in first differentiated data at $1 \%$ significant level. However, we find that prices of Korean cattle and Australian beef have unit root without trend whereas they have no unit root with the trend in original data at 5\% significant level. For the price of corn, we find that there is unit root regardless of trend.

\section{Number of lag selection}

Table 5 shows the result from selecting a number of lags. In the original data, we find that the numbers of lags are 2, 1, and 1 based on Akaike Information Criterion (AIC), Bayesian Information Criterion (BIC), and Hannan-Quinn Information Criterion (HQC), respectively. By using the first difference data, we find that the number of lags is same as 1 for all three different criterions. According to Tsay (1984), Potscher (1989),

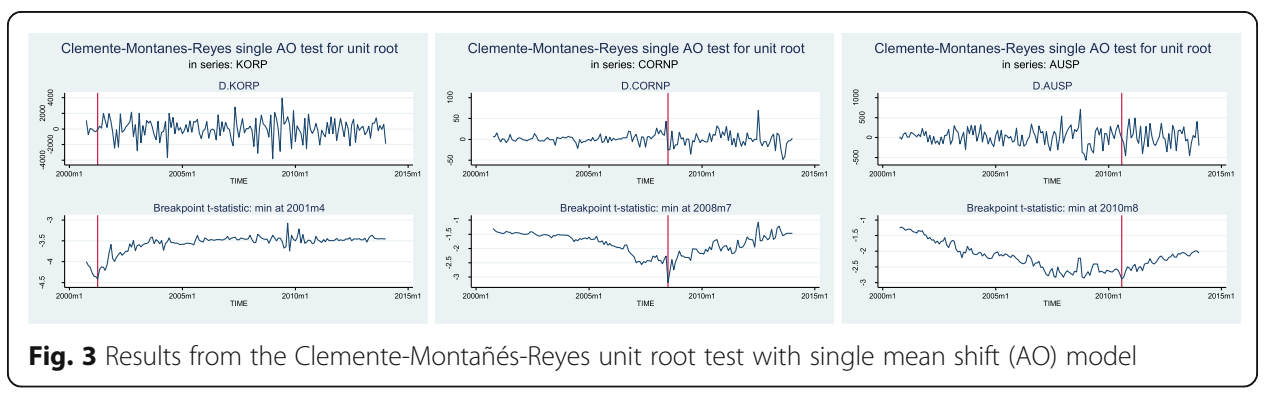


Table 4 The results from the DF-GLS Unit Root Test

\begin{tabular}{|c|c|c|c|c|c|c|}
\hline \multirow[b]{2}{*}{ Variable } & \multicolumn{2}{|l|}{ Level } & \multirow[b]{2}{*}{ Decision } & \multicolumn{2}{|l|}{ First difference } & \multirow[b]{2}{*}{ Decision } \\
\hline & $\begin{array}{l}\text { Constant w/o } \\
\text { trend }\end{array}$ & $\begin{array}{l}\text { Constant with } \\
\text { trend }\end{array}$ & & $\begin{array}{l}\text { Constant w/o } \\
\text { trend }\end{array}$ & $\begin{array}{l}\text { Constant with } \\
\text { trend }\end{array}$ & \\
\hline KORP & -1.89 & $-2.96^{* *}$ & $I(1) / I(0)$ & $-17.48^{* * *}$ & $-18.53^{* * *}$ & $I(0)$ \\
\hline CORNP & -1.01 & -1.74 & $\mathrm{I}(1)$ & $-10.75^{* * *}$ & $-10.87^{* * *}$ & $\mathrm{I}(0)$ \\
\hline AUSP & 0.32 & $-3.44^{* *}$ & $|(1) /|(0)$ & $-12.36^{* * *}$ & $-12.54^{* * *}$ & $\mathrm{I}(0)$ \\
\hline
\end{tabular}

$\mathrm{I}(0)$ indicates no unit root, and I(1) indicates unit root Estimates are statistically significant at ${ }^{* * *} 1 \%,{ }^{* *} 5 \%$

and Cavaliere et al. (2015), BIC is consistent compared to AIC because AIC overestimates with positive probability. Therefore, we use BIC information.

\section{Threshold cointegration test}

We use Seo (2006) test whether there is no cointegration or threshold cointegration between the variables. The null of no cointegration is used in Seo test. Table 6 shows the result from the test of no cointegration vs threshold cointegration. Based on the result from Seo test, we find that there is threshold cointegration between prices of Korean beef and Australian beef and between the price of Australian beef and corn with 1 lag based on the BIC. However, there is no cointegration between the price of Korean beef and corn. Therefore, we conclude that there is no cointegration among the three variables. In the Seo test, we are unable to test whether no cointegration or threshold cointegration for all the variables at the same time. For this reason, we conduct threshold cointegration test for each variable separately. Based on the result of Seo test, we conclude TVAR with first differentiated data is preferred to TVCEM since there is no cointegration between the variables.

\section{Testing threshold linearity}

Two sources primarily create nonlinearities in time series analysis. First, the structural change can create nonlinearity, according to the Giordani et al. (2007). Secondly, when larger shocks induce a different response compared to smaller shocks, it creates a dynamic response due to the presence of nonlinearity (Goodwin and Holt 1999). Goodwin and Harper (2000) found that recent time series models examining price transmission consider asymmetric adjustments linear. However, Luoma et al. (2004) argue that linear models in a nonlinear situation result in incorrect inferences. In this case, we expect there to be nonlinearities, so utilizing a linear model would not be appropriate.

To find the number of thresholds, we test threshold nonlinearity by using the Lo and Zivot test that was proposed by Hansen (1999) and developed by Lo and Zivot (2001). Utilization of this test allows for the testing of nonlinearities between price regimes, in this case, pre- and post-BSE. Table 7 shows test statistics, which are results from the threshold nonlinearity test with 1 lag based on BIC from Table 5. In Table 7, the null hypothesis of 1 vs 2 , for example, is that linear VAR model with no threshold is true

Table 5 The results from selecting number of lags

\begin{tabular}{llll}
\hline Data & AIC & BIC & HQC \\
\hline Original data & 2 & 1 & 1 \\
Differentiated data & 1 & 1 & 1 \\
\hline
\end{tabular}


Table 6 Test of no cointegration vs threshold cointegration

\begin{tabular}{llc}
\hline & Test statistic & $P$ value \\
\hline KORP vs AUSP & 12.34 & 0 \\
AUSP vs CORNP & 19.80 & 1 \\
KORP vs CORNP & 27.83 & 0 \\
\hline
\end{tabular}

model compared to the model with one threshold since 1, 2, and 3 indicate no threshold, 1 threshold, and 2 thresholds, respectively. Therefore, if we reject the null hypothesis of 1 vs 2 , we conclude that the linear VAR model with one threshold is a true model. Based on the results in Table 7, we find that only differentiated Australian beef price has 2 thresholds at $1 \%$ significant level whereas other variables have no thresholds. Therefore, we focus only on TVAR with 2 thresholds in first differentiated Australian beef price even though we want to examine the effect on corn price.

\section{Threshold vector autoregressive model}

Since we find that there are 2 thresholds in first differentiated Australian beef price. The TVAR model can be defined as the equation below:

$$
y_{t}=\left\{\begin{array}{lr}
\delta_{1}+\rho_{1,1} y_{t-1}+\cdots+\rho_{1, \rho} y_{1-p 1}+u_{t} & \text { if } x_{t-d} \geq \theta_{L} \\
\delta_{2}+\rho_{2,1} y_{t-1}+\cdots+\rho_{2, \rho} y_{1-p 1}+u_{t} & \text { if } \theta_{H} \geq x_{t-d} \geq \theta_{L} \\
\delta_{3}+\rho_{3,1} y_{t-1}+\cdots+\rho_{3, \rho} y_{1-p 1}+u_{t} & \text { if } \theta_{H} \geq x_{t-d}
\end{array}\right.
$$

where $y$ is price vector of Korean beef, corn, and Australian beef, $\delta_{1}, \delta_{2}, \delta_{3}$ refer to the intercepts in each regime, $\rho_{j, 1}, \ldots, \rho_{j, m-1}$ are the number of lags in regime, $\theta_{L}, \theta_{H}$ are the thresholds, $d$ is the delay of transition variable, and $x_{t-d}$ is the transition variable from one of three variables. To find 2 threshold points, a grid search is used in this study. Based on Stigler (2010), the grid search is to find threshold points $(\theta)$ that minimize the sum of squares and maximize the log-likelihood. The objective function is defined as follows:

$$
\hat{\theta}=\operatorname{argmin} \operatorname{SSR}(\theta)
$$

The values of the variables are sorted, and a minimal number of observations in each regime are ensured through a grid search by excluding a certain percentage of the first and last values. Then, the SSR is estimated for each selected value, and the one that minimizes the SSR is taken as the estimator.

Table 8 shows the results from the TVAR model with 2 thresholds, which are -275.15 and 198.29, in Australian beef price, in addition, $11.4 \%$ of observations in the first regime, $69.3 \%$ in the second regime, and $19.3 \%$ in the third regime, respectively.

Table 7 Results of test statistics from the threshold nonlinearity test

\begin{tabular}{llcr}
\hline Threshold hypothesis & DAUSP & DCORNP & DKORP \\
\hline 1 vs 2 & $35.30^{* * *}$ & 16.69 & 19.41 \\
1 vs 3 & $62.30^{* * *}$ & 28.86 & 42.41 \\
2 vs 3 & $27.01^{* * *}$ & 12.17 & 23.00 \\
\hline
\end{tabular}

D indicates first difference Significant at ${ }^{* *} 1 \%$ 
Table 8 Results from the TVAR model in Australian beef price

\begin{tabular}{|c|c|c|c|c|c|c|c|c|c|}
\hline & Regime & Intercept & & DAUSP (-1 & & DCORNP (-1) & & $\operatorname{DKORP}(-1)$ & \\
\hline \multirow{3}{*}{$\begin{array}{l}\text { DAUSP } \\
(11.40 \%)\end{array}$} & 1 & -157.462 & & -0.840 & & 3.172 & & 0.030 & \\
\hline & 2 & 10.883 & & -0.053 & & -0.001 & & 1.489 & \\
\hline & 3 & 33.261 & & -0.163 & & -1.797 & & -0.019 & \\
\hline \multirow{3}{*}{$\begin{array}{l}\text { DCORNP } \\
(69.30 \%)\end{array}$} & 1 & -14.893 & & -0.036 & & 0.090 & & -0.001 & \\
\hline & 2 & 0.183 & & -0.001 & & 0.183 & $* * *$ & -0.003 & * \\
\hline & 3 & -5.032 & & 0.019 & & 0.152 & & -0.001 & \\
\hline \multirow{3}{*}{$\begin{array}{l}\text { DKORP } \\
(19.30 \%)\end{array}$} & 1 & 1992.633 & $* * *$ & 5.037 & $* * *$ & -39.993 & $* * *$ & -0.599 & $* * *$ \\
\hline & 2 & 130.931 & & 1.489 & $* * *$ & 1.426 & & -0.297 & $* * *$ \\
\hline & 3 & -335.071 & & 0.067 & & 22.135 & $* * *$ & -0.397 & * \\
\hline
\end{tabular}

Threshold value: -278.15 and 198.29 . Percentage of observations in each regime: $11.4,69.3$, and $19.3 \%$. Note: $(-1)$ indicates first lag

Significant level: ***1\% and ${ }^{*} 10 \%$

Figure 4 visually shows the results from threshold points and grid search. From here, the name of each variable represents first difference for simplicity.

In the first regime, which indicates decreasing in Australian beef price (less than -278.15 threshold), we find that current Korean beef price is positively and significantly affected by a previous month of Australian beef price at 5\% significant level, and it can be explained by substitutability between Australian beef and Korean beef. For corn, if corn price increased in the previous month, there is an incentive to increase current Korean beef price, but the incentive is canceled out (i.e., buffered) due to weak Australian beef price.

In the second regime, which indicates less volatility in Australian beef price compared to other two extreme cases (i.e., first and third regime), we find that change in previous corn price has no significant impact on Korean beef price compared to extreme cases; in addition, change in previous Australian beef price has significant impact on Korean beef price at $5 \%$ level.

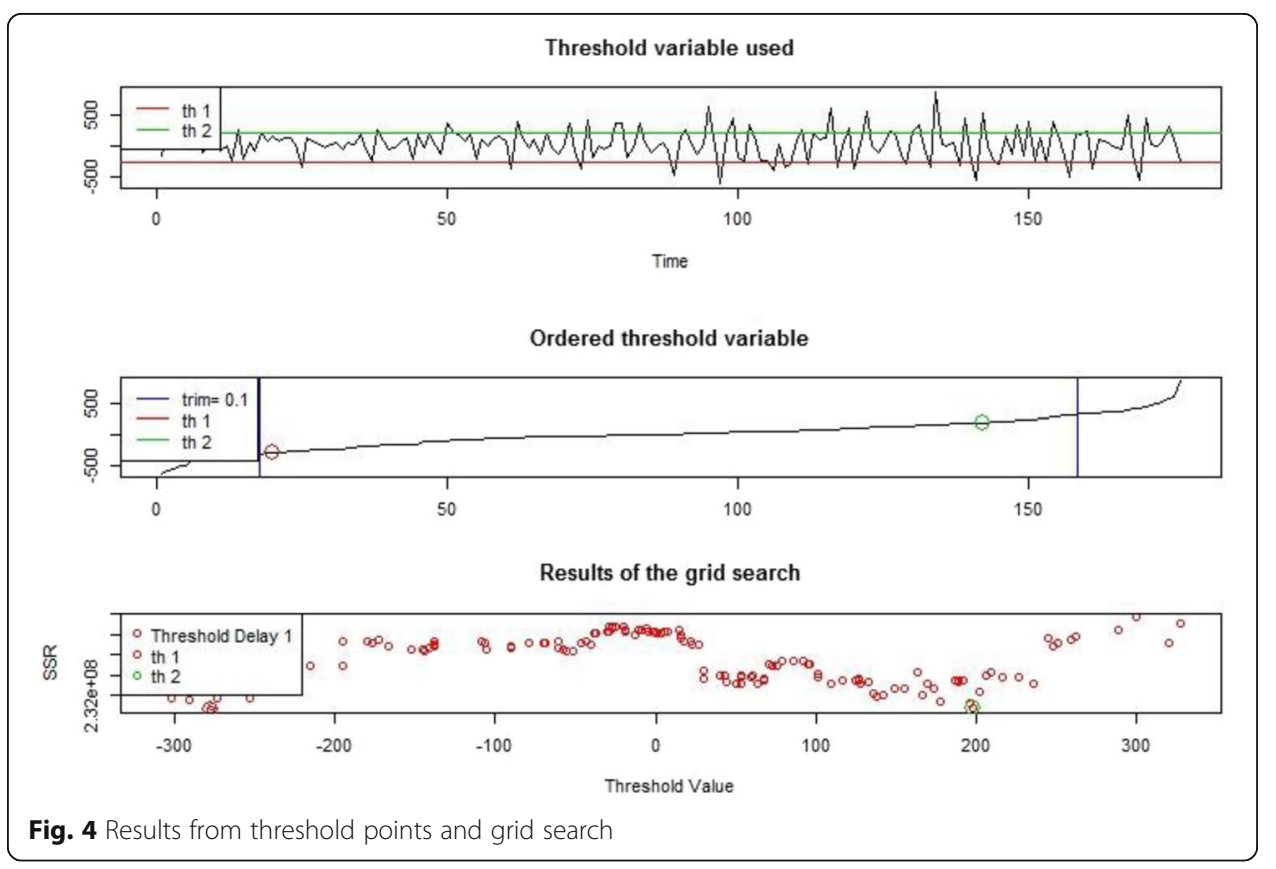


In the third regime, which indicates increasing in Australian beef price (greater than 198.23 threshold), we find that current Korean beef price is affected positively by previous corn price at $5 \%$ and negatively by previous Korean beef price at $1 \%$ significant level respectively whereas no impact from previous Australian beef price. Results from the third regime can be explained that there is an incentive to increase Korean beef price as corn price increases, and the incentive cannot be canceled out in this regime due to increasing price in substitute good (Australian beef).

\section{Discussion}

Korea is one of the largest beef import countries in the world with the majority coming from Australia, USA, and New Zealand. The primary objective of this study is to evaluate the relationships between the prices of the Korean native cattle, world corn price, and imported Australian beef price. In 2003, the outbreak of BSE in the USA, the second largest exporter of beef to South Korea, resulted in a ban on US beef imports until July 2008, thus created an expected structural break in Korean native beef prices. Secondly, given the dynamic changes that take place in the prices used in the model, the potential for nonlinearities in regimes thresholds are evaluated.

The structural breakpoints are estimated by using Clemente-Montañés-Reyes unit root test with single mean shift and AO model. A structural break is found for Korean native beef price in April 2001, world corn price in July 2008, and Australian imported beef price in August 2010. Even considering the structural breaks, the data is still nonstationary. Additionally, given the data limitations on observations pre or post the structural breaks, the estimation of a long-run relationship is not possible. However, the existence of these structural breaks does provide evidence that there could be nonlinearity in the data (Giordani et al. 2007). Given this evidence, a threshold framework is employed to investigate the presence of nonlinearity from fluctuations in the original data.

This study employs a threshold framework to examine nonlinearity between the variables by hypothesizing that price effects are statistically different at certain threshold points. Based on threshold cointegration test and the Lo and Zivot test, we find that there is threshold cointegration between prices of Korean beef and Australian beef and between the price of Australian beef and corn. In addition, differentiated Australian beef price has two thresholds at $1 \%$ significant level. The existence of a threshold in price variable supports the presence of nonlinearity and infers the different effect of the parameter (i.e., price effect) in three different regimes based on two threshold points.

We find that there are two thresholds in Australian beef price using the first difference. Also, we find there is no cointegration among three variables, so we use TVAR model. We find from the TVAR that the current Korean native beef price is positively affected by increasing in the previous month of Australian beef price in each regime even though Australian beef is a substitute for Korean native beef. This can be explained that Korean beef price is relatively higher than Australian beef price, so shocks in Australian beef price are buffered by the price difference. Changing in previous corn price has no significant impact on current Korean native beef price in the second regime. If corn price increased in the previous month, there is an incentive to increase current Korean beef price, but the incentive is canceled out (i.e., buffered) by low Australian beef price in the first regime. However, the incentive is not buffered in the third regime where increasing in previous Australian beef price is high. 


\section{Conclusions}

In summary, this study finds evidence that a BSE outbreak in the USA did impact the price relationships between Korean native beef price, world corn price, and Australian import beef price. This finding is consistent with previous studies for other countries that find BSE outbreaks fundamentally change price relationships. Furthermore, this study found that three different price regimes exist for Australian beef prices. Korean native beef prices are found to be highly sensitive to declining Australian beef prices, as shown in regime one. Therefore, Korean native beef producers and policy makers need to consider Australian beef import price as an indicator of Korean native beef production, given their high cost of production, land constraints, and the price premium for high-quality Han-Woo beef.

\section{Authors' contributions}

GK is the primary architect of this manuscript. He is responsible for collecting the data, modeling of the data, and drafting the manuscript. TM's primary role in the paper is revision of the draft manuscript and guidance on additional modeling questions. Both authors have read and approve the final manuscript.

\section{Authors' information}

GK is a third year graduate student at the University of Kentucky from South Korea. GK's primary emphasis areas are in natural resources and production economics. TM is a production economist that has interests in livestock production and policy both within and outside the USA. He has worked on a wide range of projects within the agricultural sector. However, this is his first experience with the South Korean beef market.

\section{Competing interests}

The authors declare that they have no competing interests.

Received: 4 April 2016 Accepted: 24 February 2017

Published online: 16 March 2017

\section{References}

Abdulai A (2002) Using threshold cointegration to estimate asymmetric price transmission in the Swiss pork market. Appl Econ 34:679-687

Balke NS, Fomby TB (1997) Threshold cointegration". Int Econ Rev 38(3):627-645

Baum CF (2001) Stata: the language of choice for time series analysis. Stata J 1:1-16

Cavaliere $\mathrm{G}$ et al (2015) Lag length selection for unit root tests in the presence of nonstationary volatility. Econ Rev 34:512-536

Cook R (2016). "World beef imports: ranking of countries." [online] http://beef2live.com/story-world-beef-importsranking-countries-0-106900. (Accessed 01 Dec 2016)

Elliott G, Rothenberg TJ, Stock JH (1996) Efficient tests for an autoregressive unit root. Econometrica 64:813-836

Giamalva J (2013) "Korea's demand for US Beef." Journal of International Commerce and Economics. http://www.usitc. gov/journals

Giordani P, Kohn R, van Dijk D (2007) A unified approach to nonlinearity, structural change, and outliers. J Econ 137:112-133

Goodwin BK, Harper DC (2000) Price transmission, threshold behavior, and asymmetric adjustment in the US pork sector. J Agric Appl Econ 32:543-553

Goodwin BK, Holt MT (1999). "Price transmission and asymmetric adjustment in the US beef sector." American Journal of Agricultural Economics 81:630-637

Hansen B (1999) Testing for linearity. J Econ Surv 13:551-576

Hassouneh I, Serra T, Gil JM (2010) Price transmission in the Spanish bovine sector: the BSE effect. Agric Econ 41:33-42

Hebert CJ, Anderson BC (2011) "The exogenous effect of corn prices on beef prices in the US using R\&D as an instrumental variable." Economics Honors Thesis, Colgate University

Jin YH, Power GJ, Elbakidze L (2008) The impact of North American BSE events on live cattle futures prices. Am J Agric Econ 90:1279-1286

Korea Institute for Animal Products Quality Evaluation (2013) [online] http://www.ekape.or.kr/view/user/main/main.asp. (Accessed 10 Apr 2015)

Lloyd TA et al (2006) Food scares, market power and price transmission: the UK BSE crisis. Eur Rev Agric Econ 33:119-147

Lo MC, Zivot E (2001) Threshold cointegration and nonlinear adjustment to the law of one price. Macroecon Dyn 5:533-576

Luoma A, Luoto J, Taipale M (2004) Threshold cointegration and asymmetric price transmission in Finnish beef and pork markets: Pellervo Economic Research Institute. https://www.researchgate.net/profile/Arto_Luoma/publication/ 242238244_Threshold_cointegration_and_asymmetric_price_transmission_in_Finish_beef_and_pork_markets/links/ 5735bc5a08ae298602e08bfb.pdf

Marsh JM, Brester GW, Smith VH (2008) Effects of North American BSE events on US cattle prices. Appl Econ Perspect Policy 30:136-150

Ministry of Agriculture, Food and Rural Affairs (2015) [online] http://english.mafra.go.kr/main.jsp. (Accessed 05 Apr 2015)

Park M, Jin YH, Bessler DA (2008) The impacts of animal disease crises on the Korean meat market. Agric Econ 39:183-195

Perron P (1990) Testing for a unit root in a time series with a changing mean. J Bus Econ Stat 8:153-162

Perron P, Vogelsang TJ (1992) Nonstationarity and level shifts with an application to purchasing power parity. J Bus Econ Stat 10:301-320 
Potscher B (1989) "Model selection under nonstationarity: autoregressive models and stochastic linear regression models." The Annals of Statistics. 17:1257-1274

Saghaian SH (2007) Beef safety shocks and dynamics of vertical price adjustment: the case of BSE discovery in the US beef sector. Agribusiness 23:333-348

Sanjuan Al, Dawson PJ (2003) Price transmission, BSE and structural breaks in the UK meat sector. Eur Rev Agric Econ 30:155-172

Seo M (2006) Bootstrap testing for the null of no cointegration in a threshold vector error correction model. J Econ 134:129-150

Serra T, Gil JM, Goodwin BK (2006) Local polynomial fitting and spatial price relationships: price transmission in EU pork markets. Eur Rev Agric Econ 33:415-436

Stock JH, Watson MW (2012) Introduction to Econometrics: Global Edition: Pearson Education

Tsay RS (1984) "Order selection in nonstationary autoregressive models." The Annals of Statistics. 12:1425-1433

U.S Department of Agricultural, Economic Research Service. (2012) [online] https://www.ers.usda.gov/topics/animal-products/ cattle-beef/trade.aspx. (Asscessed 15 Apr 2015)

Zivot E, Wang J (2007) Modeling financial time series with S-Plus ${ }^{\circledast}$ : Springer Science \& Business Media

Submit your manuscript to a SpringerOpen ${ }^{\circ}$ journal and benefit from:

- Convenient online submission

- Rigorous peer review

- Immediate publication on acceptance

- Open access: articles freely available online

- High visibility within the field

- Retaining the copyright to your article

Submit your next manuscript at $>$ springeropen.com 